\title{
Crescimento de mudas de peroba rosa em resposta à inoculação com fungos micorrízicos arbusculares
}

\author{
Growth responses of peroba rosa seedlings due to arbuscular mycorrhizal fungi inoculation
}

\author{
Oswaldo Machineski ${ }^{I}$ Elcio Liborio Balota ${ }^{I}$ Arnaldo Colozzi Filho' ${ }^{\mathrm{I}}$ Diva Souza Andrade \\ José Roberto Pinto de SouzaII
} \begin{abstract}
O objetivo neste trabalho foi de avaliar o efeito da
inoculação de fungos micorrízicos arbusculares no crescimento RESUMO de mudas de peroba rosa (Aspidosperma polyneuron). $O$ experimento foi conduzido em delineamento experimental, inteiramente casualizado, em casa de vegetação com seis repetições. Utilizou-se mistura de solo e areia (3:1), desinfestado como substrato, com os seguintes tratamentos de inoculação: Gigaspora margarita, Glomus clarum, Scutellospora heterogama, Acaulospora scrobiculata e uma mistura de fungos micorrízicos arbusculares (FMA). Após 120 dias, observou-se que a colonização micorrízica radicular foi de $28,3 \%$ a $48,4 \%$ para a mistura de FMA e para G. margarita, respectivamente. As plantas inoculadas com G. margarita e G. clarum apresentaram maior crescimento, indicando o potencial da inoculação desses fungos na produção de mudas.
\end{abstract}

Palavras-chave: Aspidosperma polyneuron, Acaulospora scrobiculata, Gigaspora margarita, Glomus clarum, Scutellospora heterogama.

\section{ABSTRACT}

The aim of this study was to examine the effects of arbuscular mycorrhizal fungi (AMF) inoculation on Aspidosperma polyneuron seedlings growth. The experiment was conducted under greenhouse conditions in a randomized design using a disinfected mixture of soil + sand (3:1) with the following treatments: Gigaspora margarita, Glomus clarum, Scutellospora heterogama, Acaulospora scrobiculata, a mixture of arbuscular mycorrhizae fungi (AMF) and a non-inoculated control with six replicates. After 120 days of seed germination, it was observed that root colonization was from $28.3 \%$ to $48.4 \%$ for mixture of AMF and G. margarita, respectively. The plants inoculated with G. margarita or G. clarum showed higher growth than other treatments, which evidence the potential of AMF inoculation in seedlings production.

Key words: Aspidosperma polyneuron, Acaulospora scrobiculata, Gigaspora margarita, Glomus clarum, Scutellospora heterogama.

A peroba-rosa (Aspidosperma polyneuron M. Arg.) é uma espécie pertencente à família Apocynaceae, nativa da Floresta Estacional Semidecidual, ameaçada de extinção (CARVALHO, 1994). Os fungos micorrízicos arbusculares (FMA) associam-se às raízes das plantas, formando uma simbiose mutualística com benefício para ambos os organismos. Desse modo, é importante avaliar a efetividade micorrízica nessas espécies arbóreas e a contribuição dessa associação no seu desenvolvimento. Assim, o objetivo neste trabalho foi o de avaliar o crescimento inicial de peroba rosa inoculada com quatro espécies e uma mistura de FMA, em substrato ácido e de baixa fertilidade.

O experimento foi conduzido em casa de vegetação, em vasos de $3,5 \mathrm{~kg}$, contendo solo argiloso, coletado da camada 0 -20cm sob vegetação de mata, misturado com areia (3:1) e desinfestado. O substrato (solo+areia) apresentou as seguintes características

\footnotetext{
Instituto Agronômico do Paraná (IAPAR), Laboratório de Microbiologia de Solos, Área de Solos. Rod. Celso Garcia Cid, Km 375, CP 381, 86047-970, Londrina, PR, Brasil. Programa de Pós-graduação em Agronomia, Centro de Ciências Agrárias (CCA)/ Universidade Estadual de Londrina (UEL), Londrina, PR, Brasil. E-mail: omachine@iapar.br. Autor para correspondência.

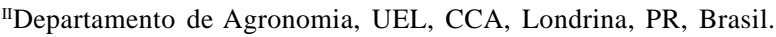


químicas: $\mathrm{pH}=5,1\left(\mathrm{CaCl}_{2} 0,01 \mathrm{M}\right) ; \mathrm{P}=2,2\left(\mathrm{mg} \mathrm{dm}^{-3}\right), \mathrm{C}=$ $5,49\left(\mathrm{~g} \mathrm{dm}^{-3}\right) ; \mathrm{H}+\mathrm{Al}=3,42 ; \mathrm{Ca}=1,75$ e $\mathrm{Mg}=0,58$, e K =

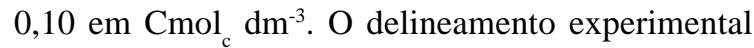
utilizado foi inteiramente casualizado com os seguintes tratamentos: (i) controle sem inoculação; (ii) Gigaspora margarita (BECKER \& HALL); (iii) Glomus clarum (NICOLSON \& SCHENCK); (iv) Acaulospora scrobiculata (TRAPPE); (v) Scutellospora heterogama (GERDEMANN \& TRAPPE), e (vi) mistura de FMA, em seis repetições. Os FMAs foram obtidos da coleção do Instituto Agronômico do Paraná, IAPAR. As sementes da peroba rosa foram obtidas junto ao Instituto de Pesquisa e Estudos Florestais (IPEF), germinadas em areia esterilizada e transplantadas para os vasos quando atingiram $5 \mathrm{~cm}$ de altura. A inoculação foi realizada no momento do transplantio com utilização de $50 \mathrm{~mL}$ de solo, contendo, aproximadamente, 200 esporos de cada espécie de FMA. No tratamento controle, foi adicionado $50 \mathrm{~mL}$ de solo desinfestado, o mesmo utilizado na inoculação, para compensar as diferenças químicas do solo. Visando à reposição da microbiota, para manter o equilíbrio entre os tratamentos, foi realizada a aplicação de $10 \mathrm{~mL}$ de um filtrado do solo inóculo, livre de propágulos de fungos MA, em cada vaso. A cada 20 dias, foi aplicado $10 \mathrm{~mL}$ de solução nutritiva de Hoogland sem P, diluída dez vezes. A umidade do solo foi mantida em $60-70 \%$ da capacidade de campo. A cada 15 dias, foi avaliada a altura de plantas (cm) e, após 120 dias, a massa seca da parte aérea e raízes (g). Os teores de nutrientes, da parte aérea, foram determinados, conforme procedimentos descritos por MIYAZAWA et al. (1992). A taxa de colonização radicular e o número de esporos de FMA foram avaliados em microscópio estereoscópio. A colonização foi realizada pelo método da placa quadriculada e a esporulação após a extração por peneiramento úmido, seguido de centrifugação em sacarose $50 \%$, de acordo com as metodologias descritas por COLOZZI FILHO \& BALOTA (1994). Dados de colonização (col) foram transformados para ARCSEN $\sqrt{\mathrm{x} / 100}$ e de esporos para $\sqrt{\mathrm{x}+1}$. Os dados foram submetidos à análise de variância e teste de Tukey a 5\% de probabilidade de erro. Os dados do crescimento relativo de plantas foram submetidos à regressão polinomial.

O crescimento relativo da peroba rosa (diferença do crescimento das plantas inoculadas e controle) evidenciou, que nos primeiros 30 dias, a inoculação proporcionou, de forma geral, aumento no crescimento, com exceção do tratamento com a mistura de FMA (Figura 1a). Entre o $30^{\circ}$ e $45^{\circ}$ dias após o plantio, houve uma diminuição na taxa de crescimento relativo nas plantas inoculadas. Essa diminuição pode ter ocorrido devido ao desenvolvimento e disseminação do micélio fúngico internamente às raízes e na região da rizosfera, ocorrendo assim, grande demanda dos FMAs pelos fotossintatos produzidos pela planta. Nessas condições, quando ocorre diminuição na taxa de crescimento da planta, o fungo pode estar se comportando como parasita, porque, nos estágios iniciais da infecção micorrízica, ocorre competição entre a planta e o fungo por fotossintatos (SILVEIRA, 1992). Após o período inicial de formação da micorrização, as plantas se desenvolveram de forma diferenciada de acordo com cada tratamento utilizado. Aos 120 dias após o plantio, as plantas inoculadas com $\boldsymbol{G}$. margarita e $\boldsymbol{G}$. clarum apresentaram altura relativa, significativamente superior ao controle (81,4 e 49,6\%) respectivamente. Mesmo não significativos, os tratamentos com A. scrobiculata e mistura de FMA proporcionaram aumento na altura relativa das plantas (8,8 e 14,2\%), respectivamente. Apenas Scutellospora heterogama proporcionou desenvolvimento inferior ao controle.

As plantas, inoculadas com G. margarita e G. clarum proporcionaram aumentos significativos na produção de matéria seca da parte aérea, com aumentos de 400 e $220 \%$, respectivamente (Figura 1b). Também, na produção de matéria seca de raízes, $\boldsymbol{G}$. margarita e G clarum foram significativamente, diferentes entre si e dos demais tratamentos, proporcionando aumentos de 400 e 275\% (Figura 1c), respectivamente em relação ao controle. A maior eficiência de $\boldsymbol{G}$. margarita, na produção da matéria seca das plantas, evidenciou a boa adaptabilidade dessa espécie em condições de acidez do solo, como observado anteriormente por CHU et al. (2001) em mudas de gravioleira, onde a inoculação dessa espécie aumentou significativamente a quantidade de matéria seca da parte aérea das plantas em solo ácido, tanto desinfestado como não desinfestado.

As espécies de FMA utilizadas apresentaram boa capacidade de colonização nas raízes de peroba rosa, variando de 28,3\% (mistura de FMA) a 48,4\% (G. margarita). A maior colonização radicular apresentada por $\boldsymbol{G}$. margarita relacionou-se ao maior desenvolvimento das plantas, o que não foi observado no tratamento com G. clarum, que apresentou taxa de colonização micorrízica radicular menor que as demais espécies, mas com significativo estímulo no crescimento das plantas (Tabela 1).

A esporulação de FMA não acompanhou o padrão da colonização. Foi observado que as espécies de FMA, que apresentaram menor estímulo no crescimento das plantas ( $\boldsymbol{S}$. heterogama e $\boldsymbol{A}$. scrobiculata), foram as com maior esporulação (Tabela 


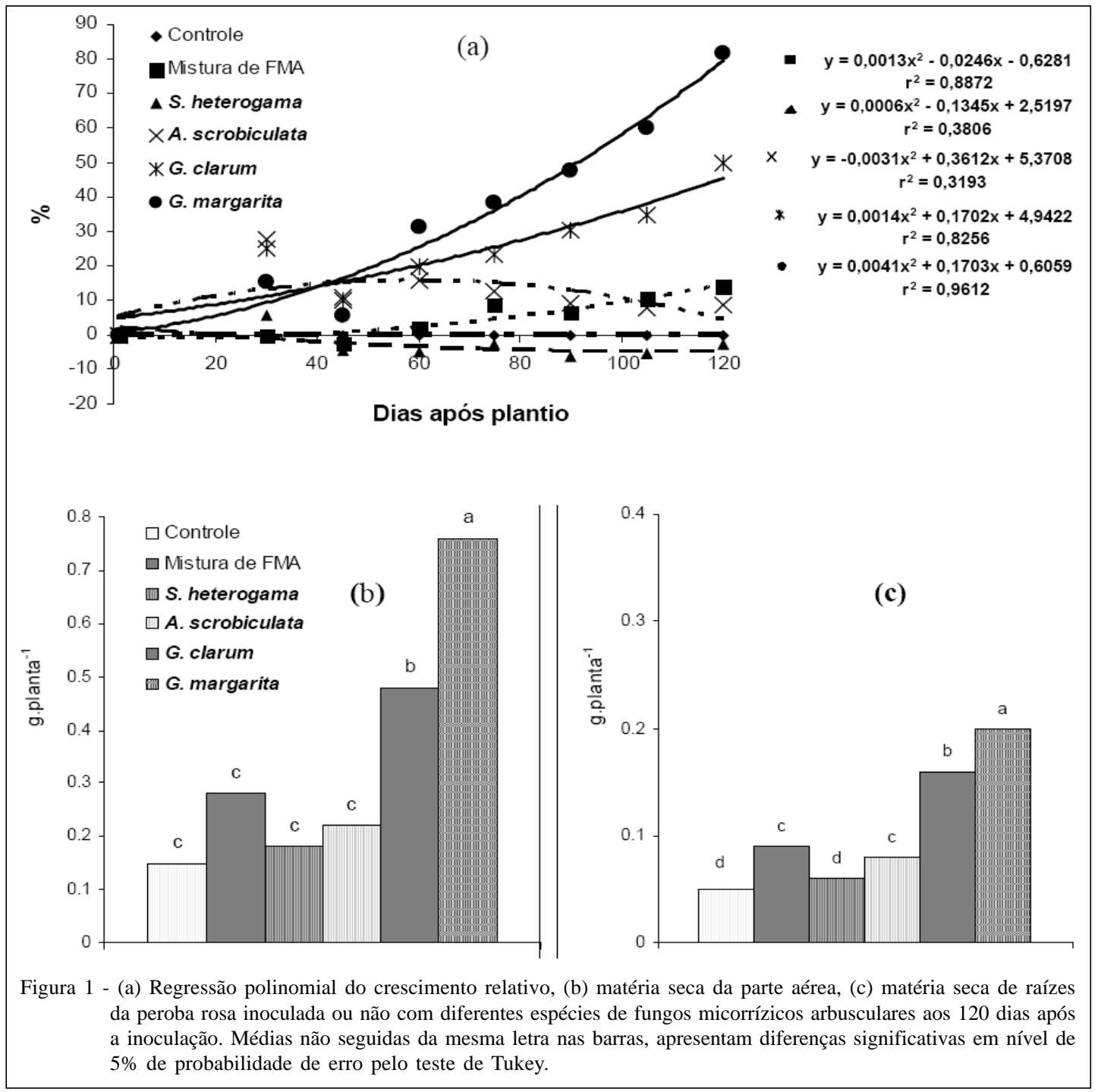

1), como observado anteriormente por CHU et al. (2001). Assim o maior número de esporos produzidos não ocorre necessariamente, devido à maior colonização radicular.

Os resultados demonstram que diferentes espécies de FMA apresentam um diferencial na capacidade de colonização (infectividade), que podem proporcionar, por sua vez, diferentes níveis de benefícios à planta. Exemplo disso foi observado nos tratamentos com $\mathbf{G}$ margarita e $\mathbf{G}$, clarum, que dentre os vários isolados testados, foram eficientes em estimular o crescimento das plantas de forma significativa em relação aos outros tratamentos com FMA e ao controle. Portanto, é importante que, para cada planta hospedeira, sejam testados diferentes isolados de FMA, pois muitos desses fungos possuem certa preferência associativa (SIEVERDING, 1991). Com a inoculação de vários isolados, é possível selecionar espécies potenciais no efetivo auxílio do crescimento de plantas em diferentes ambientes de solo. Por outro lado, tem sido relatado que as espécies do gênero Glomus sp são sensíveis à elevada acidez (SIQUEIRA et al., 1986). Talvez por esse motivo, o tratamento com G. clarum, apresentou menor eficiência no crescimento das plantas em relação ao tratamento com $\mathbf{G}$ margarita. Para os outros tratamentos utilizados, pode ter ocorrido a influência de outros fatores como nível de acidez e teor de nutrientes no solo, competição entre as espécies para o tratamento com a mistura de FMA, ou ainda, especificidade entre fungo e a planta.

Os tratamentos, inoculados com $\boldsymbol{G}$. margarita e $\boldsymbol{G}$. clarum, apresentaram maior acúmulo de nutrientes nas plantas. Esse maior acúmulo foi significativo para P, K, Ca, Mg, Cu, Zn e B (Tabela 1). 
Tabela 1 - Colonização de raízes, esporos de fungos micorrízicos arbusculares (FMA) no solo ( $\mathrm{N}^{\mathrm{o}}$ esporos 50 mL solo ${ }^{-1}$ ) e quantidade de nutrientes acumulados na parte aérea das plantas de peroba rosa, aos 120 dias após plantio.

\begin{tabular}{|c|c|c|c|c|c|c|c|c|c|c|}
\hline \multirow{2}{*}{ Tratamentos } & $\mathrm{Col}$ & Esporos & $\mathrm{P}$ & $\mathrm{K}$ & $\mathrm{Ca}$ & Mg & $\mathrm{Cu}$ & $\mathrm{Zn}$ & B & Mn \\
\hline & $\%$ & $\mathrm{~N}^{\circ}$ & \multicolumn{4}{|c|}{ 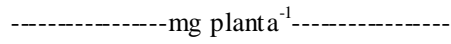 } & \multicolumn{4}{|c|}{ 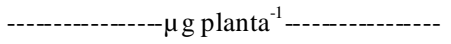 } \\
\hline Controle & $0,6 \mathrm{c}$ & $1,0 \mathrm{~b}$ & $0,1 \mathrm{c}$ & $2,3 \mathrm{c}$ & $2,8 \mathrm{c}$ & $0,3 \mathrm{e}$ & $1,5 \mathrm{c}$ & $2,8 \mathrm{c}$ & $9 \mathrm{~d}$ & $178 \mathrm{~b}$ \\
\hline Mistura FMA & $28 \mathrm{~b}$ & $1,9 \mathrm{~b}$ & $0,2 \mathrm{c}$ & $4,5 \mathrm{c}$ & $5,7 \mathrm{bc}$ & $0,7 \mathrm{c}$ & $2,4 \mathrm{bc}$ & $4,7 \mathrm{c}$ & $17 \mathrm{bc}$ & $159 \mathrm{~b}$ \\
\hline S. heterogama & $38 \mathrm{ab}$ & 11,7 a & $0,1 \mathrm{c}$ & $3,0 \mathrm{c}$ & $3,5 \mathrm{c}$ & $0,4 \mathrm{~d}$ & $1,7 \mathrm{c}$ & $3 \mathrm{c}$ & $10 \mathrm{~cd}$ & $155 \mathrm{~b}$ \\
\hline A. scrobiculata & $38 \mathrm{ab}$ & $6,8 \mathrm{ab}$ & $0,1 \mathrm{c}$ & $3,0 \mathrm{c}$ & $4,3 \mathrm{c}$ & $0,6 \mathrm{~cd}$ & $1,8 \mathrm{c}$ & $3,2 \mathrm{c}$ & $13 \mathrm{~cd}$ & $173 \mathrm{~b}$ \\
\hline G. clarum & $31 \mathrm{~b}$ & $4,0 \mathrm{ab}$ & $0,3 \mathrm{~b}$ & $7,3 \mathrm{~b}$ & $8,4 \mathrm{~b}$ & $1,1 \mathrm{~b}$ & $3,8 \mathrm{~b}$ & $7,5 \mathrm{~b}$ & $23 \mathrm{~b}$ & $301 \mathrm{a}$ \\
\hline G. margarita & $48 \mathrm{a}$ & 4,73ab & $0,5 \mathrm{a}$ & $12,5 \mathrm{a}$ & 13,8 a & $1,9 a$ & $6,5 a$ & $11,9 a$ & $32 a$ & $243 a b$ \\
\hline CV $(\%)$ & 12 & 35 & 17 & 14 & 17 & 10 & 21 & 16 & 16 & 20 \\
\hline
\end{tabular}

Médias não seguidas da mesma letra na coluna apresentam diferenças significativas em nível de 5\% de probabilidade de erro pelo teste de Tukey.

Plantas associadas a $\boldsymbol{G}$. clarum acumularam maior quantidade de $\mathrm{Mn}$ em relação ao controle, enquanto que, as inoculadas com outras espécies de FMA, não apresentaram diferenças no acúmulo de Mn. Nos demais tratamentos de inoculação, houve variações na quantidade de nutrientes acumulados na parte aérea, por exemplo, S. heterogama e A. scrobiculata influenciaram no acúmulo de Mg e a mistura de FMA no $\mathrm{Mg}$ e B.

De modo geral, as plantas inoculadas com os FMA apresentaram maior desenvolvimento e acúmulo de nutrientes. Dentre as espécies inoculadas, G. margarita e $\mathbf{G}$. clarum podem ser consideradas com potencial para serem usadas na formação de mudas de peroba rosa. Por ser de crescimento lento, a inoculação da peroba rosa com espécies eficientes de FMA, pode diminuir o tempo de formação de mudas. Mudas micorrizadas de várias espécies arbóreas, entre elas, a Aroerinha, Gravitinga, Ipê-mirim e Jambolão têm apresentado melhor desenvolvimento (CARNEIRO et al, 1996) e maior índice de sobrevivência a campo, como observado por CARNEIRO et al. (2004), em mudas de Embaúba. Esses resultados ressaltaram a importância da utilização da tecnologia de inoculação dos FMA em espécies florestais para reflorestamento, que na maioria das vezes, ocorre em solos de baixa fertilidade e com reduzido potencial de inoculo micorrízico nativo.

Pode-se concluir que a inoculação de fungos micorrízicos arbusculares promove o melhor desenvolvimento de mudas de peroba rosa em substrato ácido e de baixa fertilidade. Os fungos micorrízicos $\boldsymbol{G}$ margarita e $\boldsymbol{G}$ clarum estimulam o maior desenvolvimento vegetativo e o acúmulo de nutrientes na parte aérea de mudas de peroba rosa.

\section{REFERÊNCIAS}

CARNEIRO, M.A.C. et al. Fungo micorrízico e superfosfato no crescimento de espécies arbóreas tropicais. Scientia Forestalis, Piracicaba, n.50, p.21-36, 1996.

CARNEIRO, M.A.C. et al. Fósforo e inoculação com fungos micorrízicos arbusculares no estabelecimento de mudas de embaúba (Cecropia pachystachya Trec). Pesquisa Agropecuária Brasileira, Brasília, v.34, n.3, p.119-125, 2004.

CARVALHO, P.E.R. Espécies florestais brasileiras: recomendações silviculturais, potencialidades e uso da madeira. Colombo: EMBRAPA- CNPF, 1994. p.79-84.

CHU, E.Y. et al. Efeitos da inoculação micorrízica em mudas de gravioleira em solo fumigado e não fumigado. Pesquisa Agropecuária Brasileira, Brasília, v.36, n.4, p.671-680, 2001.

COLOZZI FILHO, A.; BALOTA, E.L. Micorrizas arbusculares. In: HUNGRIA, M.; ARAUJO, R.S. Manual de métodos empregados em estudos de microbiologia agrícola. Londrina: EMBRAPA-CNPSo, 1994. Cap.20, p.384-418.

MIYAZAWA, M. et al. Análise química de tecido vegetal. Londrina: IAPAR, 1992. 17p. (Circular, 74).

SIEVERDING, E. Vesicular-arbuscular mycorrhiza management in tropical agrosystems. Eschborn: Deutsche Gesellschaft fur Technische Zusammenarbeit, 1991. 371p.

SILVEIRA, A.P.D. Micorrizas. In: CARDOSO, E.. B.N. et al. Microbiologia do solo. Campinas: SBPC, 1992. p.257-282.

SIQUEIRA, J.O. et al. Comportamento diferenciado de fungos formadores de micorrizas vesicular-arbusculares em relação à acidez do solo. Revista Brasileira de Ciência do Solo, Campinas, v.10, n.1, p.11-16, 1986. 